\title{
PERSEPSI MAHASISWA TERHADAP PENGGUNAAN KAHOOT DI PERGURUAN TINGGI UNTUK KONTEKS BAHASA INGGRIS SEBAGAI BAHASA ASING
}

\author{
Arimuliani Ahmad ${ }^{1}$, Johari Afrizal ${ }^{2}$, Nadia Wulandari ${ }^{3}$ \\ Universitas Islam Riau, Pekanbaru, Indonesia ${ }^{1,2,3}$ \\ $\underline{\text { Arimulianiahmad@edu.uir.ac.id }^{1}}$, johariafrizal@edu.uir.ac.id ${ }^{2}, \underline{\text { nadia.wulandari@gmail.com }}{ }^{3}$
}

\begin{abstract}
The advancement of technology already contributes a crucial impact on education, especially for the English Foreign Language (EFL) context. Kahoot! is one of the innovations that teachers can use to increase student's engagement in lesson sessions as a media in the teaching and learning process. This study was conducted to investigate the students' perception of its utilization. This research was conducted with a qualitative study due to describe the students' perception of Kahoot! usage. The participants of this study were 38 students in the sixth semester of English Language Education in one of the Vocational Universities in Riau. The data were gathered through questionnaire and interview. The result showed that 10 students have a positive perception in Perceived Usefulness, 9 students have a positive perception in Perceived Ease of Use, 11 students have a positive perception in Attitude toward Using, 13 students have a positive perception in Behavioural Intention to Use, and then 3 students have a positive perception in Actual System Use. This research proved that the students' perception of Kahoot! is positive in the teaching and learning process.
\end{abstract}

Keywords: Students' perception, Kahoot, EFL context

\begin{abstract}
ABSTRAK
Kemajuan teknologi telah memberikan dampak yang sangat penting bagi dunia pendidikan, terutama untuk konteks English Foreign Language (EFL). Kahoot! merupakan salah satu inovasi yang dapat digunakan oleh guru sebagai media dalam proses belajar mengajar untuk meningkatkan keterlibatan mahasiswa dalam sesi pembelajaran. Penelitian ini dilakukan untuk mengetahui persepsi mahasiswa tentang pemanfaatannya. Penelitian ini dilakukan dengan studi kualitatif karena mendeskripsikan persepsi mahasiswa terhadap penggunaan Kahoot!. Partisipan penelitian ini adalah 38 mahamahasiswa semester enam Pendidikan Bahasa Inggris di salah satu universitas swasta di Riau. Pengumpulan data dilakukan melalui kuesioner dan wawancara. Hasil penelitian menunjukkan bahwa 10 mahasiswa memiliki persepsi positif terhadap ketergunaan, 9 mahasiswa memiliki persepsi positif dalam kemudahan penggunaan, 11 mahasiswa memiliki persepsi positif dalam sikap penggunaan, 13 mahasiswa memiliki persepsi positif dalam Intensitas penggunaan, dan kemudian 3 mahasiswa memiliki persepsi positif dalam aktualisasi siste, penggunaan. Temuan penelitian ini membuktikan bahwa persepsi mahasiswa terhadap Kahoot! positif dalam proses belajar mengajar.
\end{abstract} Kata kunci: Persepsi mahasiswa, Kahoot, konteks EFL

\section{PENDAHULUAN}

Pengintegrasian teknologi dalam pendidikan tinggi menjadi tren saat ini yang bertujuan untuk meningkatkan dinamika proses belajar mengajar untuk mencapai tujuan pembelajaran itu sendiri. Pemanfaatan teknologi ini biasanya berfokus kepada pemanfaatannya sebagai media pembelajaran (Ahmad, 2018) atau sebagai media penilaian (Ahmad, 2019; Etfita,
2019). Banyak perguruan tinggi mendukung dosennya memanfaatkan teknologi untuk mengatasi berbagai gaya belajar mahamahasiswanya karena banyak studi yang membuktikan bahwa pemanfaatan teknologi dalam pembelajaran memberika dampak yang signifikan. hal ini ditunjukkan oleh persepsi positif yang disampaikan (Afrizal et al., 2020; Dianati et al., 2020). 
Selanjutnya, banyak penelitian yang mengungkap pengaruh positif teknologi yang terintegrasi dalam proses belajar mengajar. Pertama, alat digital seperti YouTube dan Blog dapat meningkatkan penguasaan kosakata mahasiswa. Penelitian lain juga membuktikan bahwa Moodle mampu meningkatkan kemampuan mahasiswa (Wu, 2008). Selain itu, e-learning juga memberikan kontribusi yang baik terhadap kemampuan bahasa Inggris mahasiswa seperti Edmodo (Al-Naibi, 2018; Etfita, 2019), Padlet (Kleinsmith, 2017)(Ahmad, 2019), Kahoot (Ahmad, 2019), Papan Diskusi Papan Tulis, Blog dan Wiki, Whatsapp.

Diniati dkk (2020) menggunakan Kahoot sebagai media ajar yang diakses mahasiswa di rumah sebelum mereka mendiskuikannya di dalam kelas. Namun, penelitian ini menggunakan Kahoot! sebagai media pembelajaran tambahan untuk mempertajam pemahaman mahasiswa terhadap pelajaran Bahasa Inggris dan juga sebagai alat penilaian untuk mengukur hasil pembelajaran. Ini adalah bagian dari teknologi berbasis web dan juga teknologi pembelajaran seluler karena dapat diakses keduanya.

\section{Kahoot!}

Kahoot! adalah sebuah platform dengan sistem respons langsung yang melibatkan mahasiswa melalui permainan seperti kuis, diskusi, dan survei yang dibuat sebelumnya atau dadakan (Thomas, 2014). Penggunaannya dapat nginspirasi mahasiswa untuk belajar. Mudahnya, para mahasiswa tidak membutuhkan akun untuk mengakses kuis. Selain itu, ini dapat diakses oleh perangkat apa pun dengan browser web seperti iPad, perangkat Android dan IOS. Namun, guru memang membutuhkan akun untuk membuat kuis (Ahmad, 2019; Thomas, 2014).

Selanjutnya, Kahoot! bermanfaat bagi pendidik karena terlibat dalam pengenalan konten baru atau meninjau konten lama. Data dapat dikumpulkan dan ditinjau sebagai dokumen Excell untuk mengukur pemahaman mahasiswa tentang konten. Penggunaan Kahoot! dapat bervariasi dalam hal penilaian dan proyek seperti penilaian formatif, penilaian diagnostik, proyek penelitian dan presentasi (Thomas, 2014). Kahoot! memungkinkan pengguna membuat kuis yang menyenangkan. Para mahasiswa menggunakan komputer, smartphone, atau perangkat lain untuk ikut bermain. Pengguna dapat membuat kartu flash untuk ditinjau. Para pengguna juga dapat menyematkan beberapa video dan menggunakan Kahoot! sebagai bagian dari proses pengajaran atau mahasiswa dapat membuat permainan ulasan untuk tujuan berbagi.

Selanjutnya, Kahoot! adalah sebuah aplikasi, sistem respon kelas berbasis permainan, dan platform pendidikan. Kahoot! memulai diskusi yang dipimpin oleh rekan sejawat. Kahoot! terdiri dari pertanyaan pilihan ganda sebagai kuis, diskusi, atau survei dalam topik, bahasa, atau kemampuan apa pun. Ini diproyeksikan di depan kelas dan dimainkan oleh seluruh kelas bersama secara real-time. Kahoot! merupakan proyek pembelajaran berbasis permainan melalui soal pilihan ganda yang dapat dilakukan secara berkelompok atau perorangan. Kahoot! akan memberikan banyak kesenangan, menurut penjelasan bahwa dengan pandangan baru yang menyegarkan tentang pengenalan subjek dan penilaian formatif melalui kuis, kolaborasi, dan presentasi konten, Kahoot! memulai diskusi yang dipimpin oleh rekan kerja dengan menyenangkan.

Menurut Venkantesh (2002) dalam teori Technology Acceptance Model (ATM), teori yang mengukur penerimaan seseorang terhadap teknologi ditentukan oleh Perceived Usefulness, Perceived Ease of Use, Attitude to Using, Behavioral Intention to Use, dan Actual System Use. Venkantesh (2002), menyatakan bahwa terdapat beberapa komponen dasar dalam persepsi seperti persepsi (mengalami orang dan perilaku), persepsi (objek, orang, situasi, hubungan, kemudahan penggunaan, dll), konteks situasi (objek, kegunaan, atau peristiwa). ), dan proses (penggunaan dan sikap aktual). Contradict Walgito (2012), mengatakan membagi komponen menjadi 3, yaitu kognitif (persepsi yang terkait dengan pengetahuan individu, pendapat, dan kepercayaan terhadap objek yang dipersepsikan), afektif (emosional yang terkait dengan suka atau tidak suka 
terhadap objek yang dipersepsikan), dan konatif (gerakan tindakan pada objek yang dipersepsikan).

Dalam penelitian ini peneliti lebih mengutamakan pada teori Venkantesh yaitu Technology Acceptance Model (TAM) karena menawarkan indikator-indikator penerimaan teknologi yang sama, menyajikan alasan seseorang menggunakan dan menerima penggunaan teknologi secara luas, dan teori ini tidak hanya untuk mendeteksi, tetapi juga memberikan rasionalisasi. Dengan demikian, suatu penelitian dapat menemukan hal yang tidak tepat dan sesuai dalam sistem teknologi Venkantesh (2002).

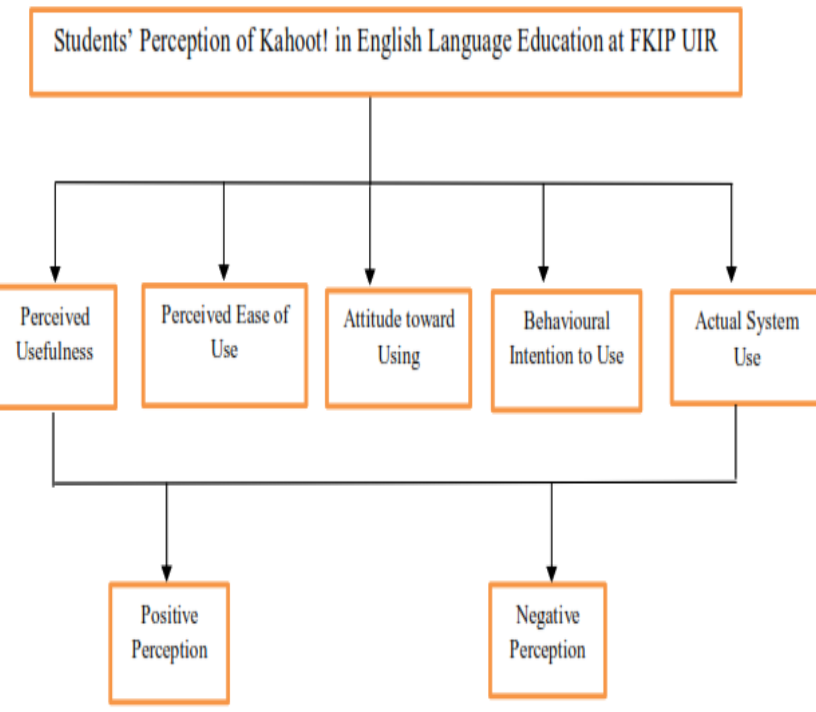

Gambar 1. TAM oleh Venkantesh (2002)

Singkatnya, penelitian ini bertujuan untuk menemukan bagaimanakah persepsi mahasiswa terhadap penggunaan Kahoot! dalam pembelajaran Bahasa Inggris di perguruan tinggi.

\section{METODOLOGI PENILITIAN}

Penelitian ini merupakan penelitian kualitatif yang mendeskripsikan fenomena persepsi mahasiswa terhadap penggunaan Kahoot dalam pembelajaran. Ada dua jenis instrument yang digunakan yakni angket dan wawancara. Subjek penelitian ini adalah 36 mahamahasiswa S1 di Program Studi
Pendidikan Bahasa Inggris di salah satu universitas swasta di Riau.

\section{HASIL DAN PEMBAHASAN}

Hasil penelian ini dijelaskan melalui pembahasan lima indikator persepsi yang yang diperoleh dari hasil angket dan didukung oleh data interview tentang keberterimaan teknologi yang dijelaskan sebagai berikut:

\section{Tabel 1. Perceived Usefulness (kemanfaatan)}

\begin{tabular}{|c|c|c|c|c|c|}
\hline $\begin{array}{c}\text { Samp } \\
\text { le }\end{array}$ & Concept & $\begin{array}{c}\text { Performa } \\
\text { nce }\end{array}$ & Features & $\begin{array}{l}\text { Benefits in } \\
\text { users } \\
\text { performance }\end{array}$ & $\begin{array}{c}\text { Popula } \\
\text { rity }\end{array}$ \\
\hline 1 & Technology & Interested & & Assignment & Good \\
\hline 2 & $\begin{array}{l}\text { Quiz and } \\
\text { process }\end{array}$ & Effective & $\begin{array}{l}\text { Discussion } \\
\text { form and } \\
\text { score }\end{array}$ & Efficient & Great \\
\hline 3 & Gaming & Interested & $\begin{array}{l}\text { Game and } \\
\text { quiz }\end{array}$ & Increase & Good \\
\hline 4 & Gaming & Amazed & All features & Efficient & Good \\
\hline 5 & Application & Effective & Game & Effective & Good \\
\hline 6 & Gaming & Interested & $\begin{array}{l}\text { Mix and } \\
\text { match }\end{array}$ & Efficient & $\begin{array}{l}\text { Not } \\
\text { Really }\end{array}$ \\
\hline 7 & $\begin{array}{l}\text { Learning } \\
\text { Media }\end{array}$ & \begin{tabular}{|l|} 
No \\
Influence
\end{tabular} & Media & Assignment & Great \\
\hline 8 & $\begin{array}{l}\text { Learning } \\
\text { Media }\end{array}$ & Interested & $\begin{array}{l}\text { Game, } \\
\text { discussion }\end{array}$ & Efficient & Good \\
\hline 9 & $\begin{array}{l}\text { Learning } \\
\text { Media }\end{array}$ & Effective & Quiz & Efficient & Good \\
\hline 10 & Application & Increased & Quiz & Efficient & $\begin{array}{l}\text { Not } \\
\text { Really }\end{array}$ \\
\hline 11 & $\begin{array}{l}\text { Learning } \\
\text { Media }\end{array}$ & Increased & Quiz & Efficient & Good \\
\hline 12 & Application & Effective & All features & Efficient & $\begin{array}{l}\text { Not } \\
\text { Really }\end{array}$ \\
\hline 13 & Application & Effective & Quiz & Efficient & $\begin{array}{l}\text { Not } \\
\text { Really }\end{array}$ \\
\hline 14 & Gaming & Effective & & Efficient & $\begin{array}{l}\text { Not } \\
\text { Really }\end{array}$ \\
\hline
\end{tabular}

Berdasarkan informasi yang disajikan pada tabel 1, dapat disimpulkan semua mahasiswa memiliki persepsi yang positif terhadap konsep Kahoot !, namun ada juga mahasiswa yang memiliki persepsi negatif terhadap kegunaan Kahoot! yakni terhadap performanya, terlihat bahwa sampel 7 tidak merasakan pengaruh dalam menggunakan Kahoot!. Hasilnya, ada 5 mahasiswa yang merasakan Kahoot! tidak terlalu populer. Dapat disimpulkan bahwa Perceived Usefulness of Kahoot! positif.

Tabel 2. Perceived Ease of Use (Kemudahan Penggunaan)

\begin{tabular}{|c|l|l|l|l|l|}
\hline $\begin{array}{c}\text { Samp } \\
\text { le }\end{array}$ & Easiness & $\begin{array}{c}\text { Innovatio } \\
\text { n }\end{array}$ & $\begin{array}{c}\text { Benefits in } \\
\text { Courses }\end{array}$ & Efficiency & $\begin{array}{c}\text { Procedur } \\
\text { es }\end{array}$ \\
\hline 1 & System & Good & Grammar & Time & Understan \\
\hline
\end{tabular}




\begin{tabular}{|c|c|c|c|c|c|}
\hline & & & & & dable \\
\hline 2 & Easier & Modern & Exercise & Effortless & $\begin{array}{l}\text { Understan } \\
\text { dable }\end{array}$ \\
\hline 3 & Easier & Efficient & Exercise & Time & $\begin{array}{l}\text { Complica } \\
\text { ted }\end{array}$ \\
\hline 4 & $\begin{array}{l}\text { Process, } \\
\text { easier and } \\
\text { time }\end{array}$ & Good & $\begin{array}{l}\text { Translation } \\
\text { and } \\
\text { grammar }\end{array}$ & $\mathrm{Cot}$ & $\begin{array}{l}\text { Understan } \\
\text { dable }\end{array}$ \\
\hline 5 & $\begin{array}{l}\text { Understan } \\
\text { ding }\end{array}$ & Go & $\begin{array}{l}\text { Reading } \\
\text { skill }\end{array}$ & Ass & $\begin{array}{l}\text { Complica } \\
\text { ted }\end{array}$ \\
\hline 6 & Easier & Good & $\begin{array}{l}\text { English } \\
\text { subject }\end{array}$ & Tim & $\begin{array}{l}\text { Complica } \\
\text { ted }\end{array}$ \\
\hline 7 & $\begin{array}{l}\text { Procedure } \\
\mathrm{s}\end{array}$ & Good & Reading & Assi & $\begin{array}{l}\text { Understan } \\
\text { dable }\end{array}$ \\
\hline 8 & $\begin{array}{l}\text { Process } \\
\text { and } \\
\text { Time }\end{array}$ & Good & $\begin{array}{l}\text { Learning } \\
\text { media }\end{array}$ & Time & $\begin{array}{l}\text { Understan } \\
\text { dable }\end{array}$ \\
\hline 9 & System & Efficient & Grammar & Cour & Effective \\
\hline 10 & Easier & Good & Reading & Efficient & $\begin{array}{l}\text { Understan } \\
\text { dable }\end{array}$ \\
\hline 11 & Easier & Good & Reading & Efficient & Easy \\
\hline 12 & System & Efficient & English & Time & Easy \\
\hline 13 & Easier & Good & All courses & Time & $\begin{array}{l}\text { Complica } \\
\text { ted }\end{array}$ \\
\hline 14 & Easier & Efficient & All s & Time & $\begin{array}{l}\text { Complica } \\
\text { ted }\end{array}$ \\
\hline
\end{tabular}

Tabel 2 menunjukkan bahwa sebagian besar persepsi mahamahasiswa positif terhadap persepsi kemudahan penggunaan Kahoot!. Mahamahasiswa tidak memiliki persepsi negatif tentang Kahoot! karena inovasi Kahoot! membuatnya lebih mudah dan lebih menarik. Semua mahasiswa merasakan pengaruh yang baik terhadap inovasi di Kahoot!. Dan kemudian, sebagian besar mahasiswa melihat Kahoot! bermanfaat untuk semua kursus. Setelah itu, sebagian besar mahasiswa merasakan pengaruh terhadap efisiensi Kahoot!. Kemudian, hanya 5 mahasiswa yang menyadari bahwa prosedur Kahoot! rumit.

Tabel 3. Attitude toward Using (sikap terhadap penggunaan)

\begin{tabular}{|c|l|l|l|l|l|}
\hline $\begin{array}{c}\text { Samp } \\
\text { le }\end{array}$ & $\begin{array}{c}\text { Opinio } \\
\mathbf{n}\end{array}$ & \multicolumn{1}{|c|}{ Display } & Suitable & $\begin{array}{c}\text { Pleasanc } \\
\mathbf{e}\end{array}$ & Favorite \\
\hline 1 & Good & Comfortable & $\begin{array}{l}\text { Not all } \\
\text { courses }\end{array}$ & Pleasant & Favorite \\
\hline 2 & Good & Understandabl & All courses & Pleasant & Favorite \\
\hline 3 & $\begin{array}{l}\text { Not } \\
\text { good }\end{array}$ & Comfortable & $\begin{array}{l}\text { Not all } \\
\text { courses }\end{array}$ & Pleasant & Not yet \\
\hline 4 & Good & Comfortable & All courses & Pleasant & Favorite \\
\hline 5 & Good & Comfortable & $\begin{array}{l}\text { Not all } \\
\text { courses }\end{array}$ & Pleasant & Favorite \\
\hline 6 & Good & Comfortable & $\begin{array}{l}\text { All courses } \\
\text { Not all } \\
\text { courses }\end{array}$ & Pleasant & Not yet \\
\hline 7 & Good & Comfortable & Favorite \\
\hline 8 & Good & Comfortable & $\begin{array}{l}\text { Not all } \\
\text { courses }\end{array}$ & Pleasant & Favorite \\
\hline
\end{tabular}

\begin{tabular}{|c|l|l|l|l|l|}
\hline 9 & Good & Comfortable & All courses & Pleasant & Favorite \\
\hline 10 & $\begin{array}{l}\text { Not } \\
\text { good }\end{array}$ & $\begin{array}{l}\text { Understandabl } \\
\text { e All courses }\end{array}$ & Yes & Not yet \\
\hline 11 & $\begin{array}{l}\text { Not } \\
\text { good }\end{array}$ & Comfortable & All courses & Pleasant & Favorite \\
\hline 12 & Good & Comfortable & $\begin{array}{l}\text { Not all } \\
\text { courses }\end{array}$ & Pleasant & Not yet \\
\hline 13 & Good & Comfortable & All courses & Pleasant & Not yet \\
\hline 14 & Good & Comfortable & $\begin{array}{l}\text { Not All } \\
\text { courses }\end{array}$ & Pleasant & Favorite \\
\hline
\end{tabular}

Berdasarkan data pada tabel 3, sebagian besar mahasiswa melihat bahwa Kahoot! adalah ide yang bagus, hanya 3 mahasiswa yang tidak menganggapnya sebagai ide yang baik. Sebagian besar mahasiswa merasa tampilan yang nyaman, terutama 7 mahasiswa yang melihat Kahoot! tidak cocok diterapkan di semua mata kuliah. Tapi, kebanyakan dari mereka senang menggunakan Kahoot!, mereka sangat menyenangkan belajar dengan Kahoot! Kalau begitu, Kahoot! Dalam proses pembelajaran sudah menjadi media pembelajaran favorit mereka, hanya 5 mahasiswa yang merasa kurang

Tabel 4. Behavioral Intention to Use (Niat Perilaku untuk Menggunakan Penggunaan)

\begin{tabular}{|c|c|c|c|c|c|}
\hline \begin{tabular}{|c|} 
Sam \\
ple
\end{tabular} & $\begin{array}{c}\text { Suggest } \\
\text { ion }\end{array}$ & $\begin{array}{c}\text { Importanc } \\
\text { e }\end{array}$ & $\begin{array}{l}\text { Long } \\
\text { term use }\end{array}$ & Impact & Experience \\
\hline 1 & Useful & Increase & No & Efficient & $\begin{array}{l}\text { Knowledge } \\
\text { enhancement }\end{array}$ \\
\hline 2 & Useful & Assignment & If needed & $\begin{array}{l}\text { Efficient } \\
\text { and } \\
\text { interesting }\end{array}$ & $\begin{array}{l}\text { Knowledge } \\
\text { enhancement }\end{array}$ \\
\hline 3 & Useful & Necessity & If needed & $\begin{array}{l}\text { Interestin } \\
\mathrm{g} \\
\text { but not } \\
\text { efficient }\end{array}$ & $\begin{array}{l}\text { More } \\
\text { interesting }\end{array}$ \\
\hline 4 & Useful & Assignment & Yes & $\begin{array}{l}\text { Easier, } \\
\text { but } \\
\text { time }\end{array}$ & $\begin{array}{l}\text { Knowledge } \\
\text { enhancement }\end{array}$ \\
\hline 5 & \begin{tabular}{|l|} 
Other \\
techniq \\
ue
\end{tabular} & Not really & $\begin{array}{l}\text { If lecture } \\
\text { use }\end{array}$ & Efficient & $\begin{array}{l}\text { Knowledge } \\
\text { enhancement }\end{array}$ \\
\hline 6 & Useful & Not really & Yes & Efficient & Easier \\
\hline 7 & Useful & Necessity & $\begin{array}{l}\text { If lecture } \\
\text { use }\end{array}$ & $\begin{array}{l}\text { Efficient } \\
\text { but not } \\
\text { confident }\end{array}$ & $\begin{array}{l}\text { More } \\
\text { efficient }\end{array}$ \\
\hline 8 & Useful & Increase & $\begin{array}{l}\text { Yes, If } \\
\text { needed }\end{array}$ & $\begin{array}{l}\text { Efficient } \\
\text { but } \\
\text { needed } \\
\text { focus }\end{array}$ & $\begin{array}{l}\text { More } \\
\text { efficient }\end{array}$ \\
\hline 9 & Useful & Increase & $\begin{array}{l}\text { Yes, } \\
\text { often }\end{array}$ & Efficient & Efficient \\
\hline 10 & Useful & Necessity & If needed & Efficient & Easier \\
\hline 11 & Useful & Not really & If needed & Efficient & More efficient \\
\hline 12 & Useful & Increase & If needed & Efficient & More interest \\
\hline
\end{tabular}




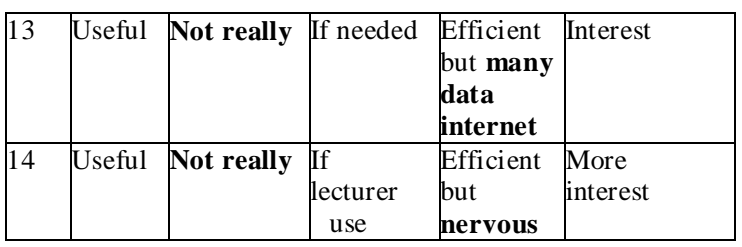

Seperti yang ditunjukkan pada tabel 4 , sebagian besar mahasiswa menyarankan untuk menggunakan Kahoot!, hanya satu mahasiswa yang memiliki saran untuk mencari teknik lain dalam proses pembelajaran dengan menggunakan Kahoot! Ada 5 mahasiswa yang merasakan Kahoot! tidak terlalu penting bagi mereka. Mayoritas mahasiswa akan menggunakan Kahoot! Untuk hari-hari mendatang, hanya 1 mahasiswa yang masih belum yakin apakah akan menggunakannya atau tidak. Semua mahasiswa mempersepsikan positif dan negatif dalam Kahoot!, ada beberapa mahasiswa yang bermasalah dengan koneksi jaringan dan waktu mengerjakan tugas. Namun ada 9 mahasiswa yang hanya merasakan dampak positif dari Kahoot!.

Berdasarkan pengalaman mereka, sebagian besar mahasiswa merasakan perbedaan setelah menggunakan Kahoot!. karena dengan menggunakan Kahoot! dapat menambah pengetahuan mahasiswa dan lebih menarik dalam belajar.

Tabel 5. Actual system Use (system yang sebenarnya)

\begin{tabular}{|c|c|c|c|c|c|}
\hline $\begin{array}{c}\text { Samp } \\
\text { le }\end{array}$ & Usage & \begin{tabular}{|c|} 
Freque \\
ncy
\end{tabular} & $\begin{array}{c}\text { Benefits in } \\
\text { applied } \\
\text { courses }\end{array}$ & Obstacle & $\begin{array}{c}\text { Satisfacti } \\
\text { on }\end{array}$ \\
\hline 1 & $1^{\mathrm{st}}$ semester & Seldom & Assignment & Net work & Simple \\
\hline 2 & $\begin{array}{l}5^{\text {th }} \\
\text { semester }\end{array}$ & Seldom & Efficient & Nothing & Efficient \\
\hline 3 & $\begin{array}{l}\text { At } \\
\text { university }\end{array}$ & Seldom & Efficient & Network & Service \\
\hline 4 & $\begin{array}{l}6^{\text {th }} \\
\text { semester }\end{array}$ & Seldom & Efficient & Time & Useful \\
\hline 5 & $\begin{array}{l}3^{\text {rd }} \\
\text { semester }\end{array}$ & Seldom & Assignment & Nothing & Useful \\
\hline 6 & $\begin{array}{l}2^{\text {nd }} \\
\text { semester }\end{array}$ & Seldom & Efficient & Network & Services \\
\hline 7 & $\begin{array}{l}\text { At } \\
\text { university }\end{array}$ & Seldom & Efficient & Nothing & Services \\
\hline 8 & $\begin{array}{l}\text { At } \\
\text { university }\end{array}$ & $\begin{array}{l}\text { Very } \\
\text { often }\end{array}$ & Efficient & $\begin{array}{l}\text { Network } \\
\text { and Data } \\
\text { packages }\end{array}$ & Useful \\
\hline 9 & $\begin{array}{l}3^{\text {rd }} \text { and } 6^{\text {th }} \\
\text { semester }\end{array}$ & Often & Evaluation & Nothing & Service \\
\hline 10 & At & Seldom & Not all & Network & Not \\
\hline
\end{tabular}

\begin{tabular}{|c|l|l|l|l|l|}
\hline & university & & courses & & really \\
\hline 11 & $\begin{array}{l}\text { At } \\
\text { university }\end{array}$ & Seldom & Effective & $\begin{array}{l}\text { Download } \\
\text { app }\end{array}$ & Services \\
\hline 12 & $\begin{array}{l}\text { At } \\
\text { university }\end{array}$ & Often & $\begin{array}{l}\text { Not all } \\
\text { courses }\end{array}$ & Network & Services \\
\hline 13 & $\begin{array}{l}\text { At } \\
\text { university }\end{array}$ & Seldom & Valuable & $\begin{array}{l}\text { Network } \\
\text { and } \\
\text { internet } \\
\text { package }\end{array}$ & $\begin{array}{l}\text { Not } \\
\text { really }\end{array}$ \\
\hline 14 & $1^{\text {st semester }}$ & Seldom & Efficient & $\begin{array}{l}\text { Network } \\
\text { and speed }\end{array}$ & Services \\
\hline
\end{tabular}

Berdasarkan hasil pada tabel 5, sebagian besar mahasiswa menggunakan aplikasi ini. Ada 10 mahasiswa yang sudah menggunakan di semester pertama saat mereka kuliah. ada 5 mahasiswa yang menggunakan Kahoot! pada semester 5, 2, 3 dan 6. Sebagian besar frekuensinya tidak sering, hanya 3 yang sering menggunakan Kahoot!. Mereka menganggap mata kuliah yang sudah menerapkan Kahoot! keuntungan keuntungan, hanya 2 mahasiswa yang tidak berpikir demikian. Permasalahan mayoritas untuk 9 mahamahasiswa tersebut adalah koneksi jaringan, satu mahamahasiswa bermasalah dengan waktu, dan hanya satu mahamahasiswa yang kesulitan mendownload aplikasi. Lalu, hanya ada 2 mahasiswa yang tidak terlalu merasakan kepuasan Kahoot!.

\section{SIMPULAN}

Berdasarkan hasil penelitian, peneliti menemukan bahwa mayoritas mahasiswa berpendapat bahwa Kahoot! sangat bermanfaat untuk membantu kinerja mereka, Hal ini dibuktikan dengan hasil positif yang idtemukan dari persipsi mahasiswa dari aspek ketermanfaatanny, kemudahan penggunaannya, intensitas penggunaannya, efisiensi penggunaaannya, dan kebenaran system penggunaannya. Hal ini sejalan juga dengan beberapa hasil penelitian persepsi mahasiswa dalam menggunakan media teknologi digital dalam pembelajaran seperti yang ditemukan oleh Etfita (2019) yang menemukan bahwa mahasiswa memiliki persepsi positif terhadap penggunaan Edmodo sebagai penilaian hasil pembelajaran bahasa Inggris. Selain itu, Charlina dan Septyanti (2019) membuktikan bahwa penggunaan Kahoot sebagai kuis online dapat motivasi mahasiswa dalam mengambil kuis. 


\section{REFERENSI}

Afrizal, J., Ahmad, A., \& Safitri, A. (2020). JSHMIC: Journal of English for Academic. J-SHMIC : Journal of English for Academic, 7(1), 66-76. https://journal.uir.ac.id/index.php/jshmic/ article/view/3905

Ahmad, A. (2018). Developing Barcorious Application as Teaching Media for English Young Students: Focus on Implication. J-SHMIC: Journal of English for Academic, 5(2), 1-14. https://doi.org/10.25299/jshmic.2018.vol5 (2). 1631

Ahmad, A. (2019). ICoSEEH 2019. Suistanable Development in Developing Country for Facing Industrial Revolution 4.0, 233-237. https://proceeding.uir.ac.id/conference/pa nel/file/1967.pdf\#page $=248$

Al-Naibi, I. h., Al-Jabri, M., and Al-Kalbani, I. (2018). Promoting students' paragraph writing using edmodo: An action research. Turkish Online Journal of Educational Technology-TOJET, 17(1):130-143.

Bawa, P. (2019). Using Kahoot to Inspire. Journal of Educational Technology Systems, 47(3), 373-390. https://doi.org/10.1177/004723951880417 3

Charlina, and Septyanti, Elvrin. (2019). Pemanfaatan media Kahoot sebagai motivasi belajar mengikuti kuis wacana Bahasa Indonesia. Geram (Gerakan Aktif Menulis), 7(2): 78-82.

Dianati, S., Nguyen, M., Dao, P., Iwashita, N., \& Vasquez, C. (2020). Student perceptions of technological tools for flipped instruction: The case of padlet, Kahoot! and cirrus. Journal of University Teaching and Learning Practice, 17(5), $1-16$.

Etfita, F. (2019). Students' Perspective on the Use of Edmodo as an Assessment Tool Fauzul. J-SHMIC : Journal of English for Academic, 6(1), 18-25. https://journal.uir.ac.id/index.php/jshmic/ article/view/2516

Thomas, J. W. (2000). A Review of Research on Project-Based Learning, 2000, http://www.bobpearlman.org/BestPractices/ PBL_Research.pdf

Kleinsmith, C. L. (2017). The effects of using padlet on the academic performance and engagement of students in a fifth grade basic skills mathematics classroom. ProQuest Dissertations and Theses, 67. Retrieved from https://search.proquest.com/docview/1900 171622 ? accountid $=15272$

Venkatesh,V., et.al. 2002. User acceptance enablers in individual decision making about technology: toward an integrated model. Decision Sciences (33) 297-316.

Wu, H. (2015). The effects of Blog-Supported collaborative writing on writing performance, writing anxiety and perceptions of EFL college students in Taiwan. (Unpublished PhD thesis, The University of South Florida, USA). 